\title{
Heat flow on hot spot swells: Evidence for fluid flow
}

\author{
Robert N. Harris ${ }^{1}$ and Marcia K. McNutt ${ }^{2}$ \\ Received 19 January 2006; revised 9 June 2006; accepted 18 August 2006; published 23 March 2007.
}

[1] We examine variability observed in heat flow determinations collected on hot spot swells. We find substantial scatter in heat flow at wavelengths of a few hundred kilometers and less at both Hawaii and Reunion, where closely spaced data exist, and large variability in the regional heat flow surveys at Cape Verde, Bermuda, and Crozet. Our preferred interpretation is that the observed variability is due to fluid flow. The presence of fluid flow admits the possibility that some heat is lost through advection such that the mean observed heat flow is less than the actual mantle flux. If so, the full magnitude of sublithospheric thermal variations may not be observed. This interpretation has important implications for understanding heat flow determinations made on hot spot swells and resulting geodynamic inferences. We suggest fluid flow may be masking variations in sublithospheric heat flux making available surface heat flow values a poor discriminator between geodynamic models for hot spot swells. Future field programs, methods of data analysis, and models should be designed to help extract a low-frequency mantle flux disguised by a high-noise surface filter.

Citation: Harris, R. N., and M. K. McNutt (2007), Heat flow on hot spot swells: Evidence for fluid flow, J. Geophys. Res., 112, B03407, doi:10.1029/2006JB004299.

\section{Introduction}

[2] Hot spot swells are large areas of anomalously shallow bathymetry associated with linear chains of volcanoes that age in the direction of plate motion. The processes generating hot spot swells are poorly understood and are undergoing a phase of renewed interest and debate because of their intimate association with the mantle plume hypothesis [Morgan, 1971]. Of the many observational constraints on the origin of hot spot swells, the interpretation of marine heat flow data is contentious. Heat flow data collected on hot spot swells have been variously used to argue for [e.g., Detrick et al., 1981; Von Herzen et al., 1982] and against [e.g., Stein and Stein, 1993; DeLaughter et al., 2005] sublithospheric thermal anomalies [Detrick and Crough, 1978; Crough, 1983]. Anomalously high heat flow observations over broad regions, combined with anomalously shallow bathymetry, and geoid highs would argue for the presence of sublithospheric thermal anomalies consistent with a mantle plume [e.g., DePaolo and Manga, 2003], whereas 'normal' heat flow values would support the contention that hot spot swells result from normal melting processes within the lithosphere [e.g., Foulger and Natland, 2003]. Heat flow anomalies are therefore one potential diagnostic for the presence or absence of a sublithospheric thermal anomaly.

\footnotetext{
${ }^{1}$ College of Oceanic and Atmospheric Sciences, Oregon State University, Corvallis, Oregon, USA.

${ }^{2}$ Monterey Bay Aquarium Research Institute, Moss Landing, California, USA.

Copyright 2007 by the American Geophysical Union. 0148-0227/07/2006JB004299\$09.00
}

[3] Two assumptions commonly guide the interpretation of heat flow data in terms of geodynamic interpretations concerning the origin of hot spot swells. The first is the choice of a reference model. Because the expected thermal anomalies are small, anomalous heat flow depends strongly on what is taken as 'normal'. Stein and Stein [1993] reviewed average heat flow values over hot spot swells relative to GDH1 [Stein and Stein, 1992], and concluded that while hot spot swells are anomalously shallow, heat flow is not anomalously high. On the basis of the presence of a bathymetric anomaly and lack of a heat flow anomaly, they argued that hot spot swells are dynamically supported. However dynamic support models also bring excess heat to the base of the lithosphere. Models that do not include excess sublithospheric heat call on heterogeneity in mantle composition to produce the observed bathymetric swell and volcanism [e.g., Bonatti, 1990; Green and Falloon, 2005; Presnall and Gudfinnsson, 2005]. The second assumption is that heat flow values represent conductive heat transfer through the lithosphere so that these values can be used to infer the thermal state at the base of the lithosphere. In fact most heat flow surveys over hot spot swells were designed assuming conductive heat transport, that heat flow would vary smoothly over large distances, and that multiple penetrations within small survey areas would average out small-scale variability. The thrust of this paper is to evaluate the validity of this second assumption. Close inspection of individual heat flow observations show that over distances of a few kilometers or less, heat flow variability can be large [Bonneville et al., 1997; Harris et al., 2000a; Von Herzen, 2004], such that this assumption may not be valid. We argue that heat flow measurements made near the axis of hot spot swells more likely reflect shallow environmental disturbances than thermal conditions at the base of the lithosphere. In 
our view the most likely source of disturbance is hydrothermal circulation and we focus on fluid flow and advective heat loss. We start by reviewing evidence for hydrothermal circulation in oceanic crust, argue that under favorable conditions fluid flow persists to crust of great age, discuss some aspects of buoyancy driven flow, and then review heat flow data collected on hot spot swells.

\section{Hydrothermal Circulation}

[4] Two characteristics of global marine heat flow data collected on oceanic crust younger than $65 \mathrm{Ma}$ indicate the prevalence of advective heat transport by hydrothermal circulation. First, heat flow values are substantially less than those predicted by conductive cooling models [e.g., Parsons and Sclater, 1977; Stein and Stein, 1994]. The discrepancy between observations and conductive predictions is used to estimate the oceanic advective heat flux [e.g., Wolery and Sleep, 1976; Stein and Stein, 1994]. Secondly, heat flow values in this environment are more variable than can be attributed to heat refraction effects due to variations in thermal conductivity or seafloor relief. This high-frequency variability most often reflects rapid fluid flow. High variability and a heat flow deficit are often found in association with each other, and this association allows the possibility of advective heat loss when high variability is observed. Even without advective heat loss, local coverage in areas of high variability may be spatially biased and not sufficient to calculate a reliable mean.

[5] In ridge flank environments, low-permeability sediments are often interrupted by high-permeability basement highs that allow recharge and discharge between the basement and overlying ocean. Lateral fluid flow through the basement aquifer between areas of recharge and discharge is the most effective geometry for widespread heat removal [e.g., Fisher et al., 2003]. Because the vast majority of heat flow observations are made with gravity driven probes that require soft sediments for insertion, lateral fluid flow is thought to bias heat flow observations toward low values. In this scenario, heat that would otherwise be conducting through the overlying sediment cover discharges through bare rock environments that are not sampled. Open circulation flow systems generate high heat flow variability through variations in sediment thickness coupled with the extent of isothermality at the top of the basement [Davis et al., 1989] and the distribution of permeability [Fisher, $1998]$.

[6] As sediment cover becomes complete, fluid flow is restricted to the underlying crust and regional advective heat loss becomes negligible. This style of flow is also associated with high variability that arises from buried basement relief, variations in the depth extent of permeability, and the ascending and descending limbs of convection.

[7] Because both styles of fluid flow are associated with high variability in heat flow values it can be difficult to discriminate between these flow styles particularly if there is insufficient bathymetric, seismic and heat flow coverage [e.g., Davis and Chapman, 1996]. Other data such as pore water geochemistry [e.g., Baker et al., 1991], age dating of basement fluids [e.g., Elderfield et al., 1999], and the chemical and mineralogic alteration of crustal rocks [e.g., Alt, 2004] can aid interpretations of hydrothermal circulation.

[8] The temporal evolution of hydrothermal circulation in oceanic crust is poorly known. Hydrothermal circulation is most vigorous at the ridge axis where thermal buoyancy driving forces are large. The vigor of fluid flow decreases off axis as the basal heat flux and permeability decreases, and relatively low permeability sediment cover increases hydraulic impedance [Anderson and Hobart, 1976; Anderson et al., 1977; Sclater et al., 1976; Stein and Stein, 1994; Fisher, 1998]. While there has been much discussion of the relative contribution of each of these mechanisms to the waning of hydrothermal circulation, it is clear that sediment cover influences hydrothermal circulation in several important ways. First, because marine sediments have very low permeability they increase the hydraulic impedance restricting flow between the basement and overlying ocean. Anderson and Hobart [1976] found that the average heat flow approaches a value in agreement with conductive cooling models when the sediment cover is reasonably continuous and thicker than about $300 \mathrm{~m}$. Secondly, seafloor relief generates lateral temperature gradients that provide a driving force for buoyant flow, and accumulations of sediment damp the surface expression of basement relief. However sediments can also enhance fluid flow because the mean basement temperature is proportional to the product of the conductive thermal gradient and sediment thickness [Fisher and Becker, 2000]. The mean basement temperature decreases the viscosity of the fluid and if a hydrothermal siphon remains active sediment cover can increase the pressure differential between recharging and discharging fluids. These factors vary from area to area depending on local basement relief, sedimentation rate, and sediment type [Spinelli et al., 2004].

[9] It is becoming clear that advectively significant hydrothermal circulation can continue into crust much older than the reported $65 \mathrm{Ma}$ "sealing age". Large variations in heat flow survey data suggest continuing hydrothermal circulation in Cretaceous aged crust [e.g., Embley et al., 1983; Noel and Hounslow, 1988; Fisher and Von Herzen, 2005]. Von Herzen [2004] recently compiled heat flow data for the purpose of assessing hydrothermal circulation in crust older than $65 \mathrm{Ma}$. On the basis of heat flow variations likely to result from thermal refraction due to basement or seafloor relief and contrasts in thermal conductivity between basement and sediment, Von Herzen [2004] concludes that it would be possible but unlikely for heat flow anomalies exceeding about $25 \%$ of the regional value to have a conductive source. Of 58 heat flow surveys on old seafloor a significant portion remain hydrothermally active.

[10] Other evidence of persisting hydrothermal circulation throughout the lifetime of oceanic crust is suggested by the significant variance in age-dependent heat flow averages [Stein and Stein, 1994], velocity logs, macroporosity data, matrix data [Jarrard et al., 2003], present-day fluid flow within $\sim 132 \mathrm{Ma}$ basement at ODP Site 1149 [Shipboard Scientific Party, 2000a], microbial alteration patterns within ODP Hole 801C [Shipboard Scientific Party, 2000b], and inferences of low-temperature fluid circulation at the Trodos ophiolote based on celadonite precipitation ages [Staudigel et al., 1986; Gallahan and Duncan, 1994]. The termination of the heat flow deficit probably signifies that advection via 

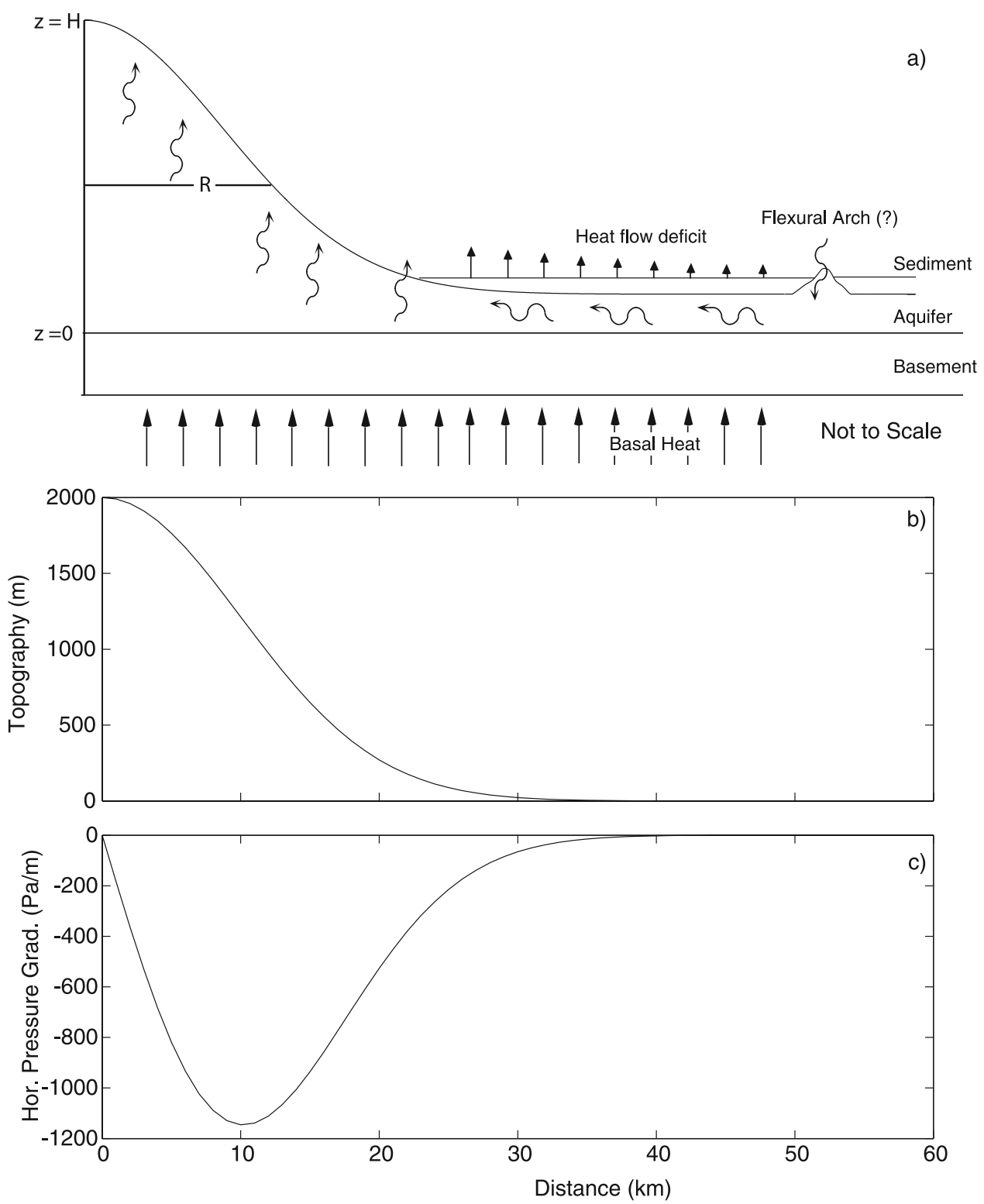

Figure 1. Conceptualization of well-mixed aquifer model [Rosenberg et al., 2000] coupled with a volcanic edifice to provide the driving force for flow. (a) Conceptual diagram of "well-mixed aquifer" model and volcanic edifice. To illustrate the important features, the diagram is not to scale. This diagram depicts the origin of a heat flow deficit, because only the heat flow across the sedimentary cover is determined. (b) Bathymetry used for model calculation. (c) Horizontal pressure gradient due to a small volcanic ridge. For this model the thermal gradient is $30 \mathrm{~K} \mathrm{~km}^{-1}$, the coefficient of thermal expansion is $1 \mathrm{e}-3 \mathrm{~K}^{-1}$, the height is $2 \mathrm{~km}$, the effective radius is $10 \mathrm{~km}$, and the reference density is $1000 \mathrm{~kg} \mathrm{~m}^{-3}$.

open circulation between the crust and the ocean is largely absent for most seafloor, rather than an ending of hydrothermal flow [Anderson and Skilbeck, 1981; Jacobson, 1992; Stein and Stein, 1994]. The picture that emerges from these studies suggests that old seafloor contains sufficient permeability to host fluid flow. Fluid flow will be significant if driving forces are sufficient, and advective heat loss will occur if the circulation system remains open. We argue that volcanic edifices associated with hot spot swells create conditions sufficient to drive advectively significant fluid flow between the ocean and basement even in mature oceanic lithosphere, and that such fluid flow might well represent an open system because of the frequent basement features penetrating the sediment cover.

\section{Buoyancy-Driven Fluid Flow}

[11] At the largest scale, fluid flow across hot spot swells is likely driven by buoyancy forces associated with two sources: the horizontal temperature gradient associated with the volcanic edifice and the pressure difference between cooler and warmer columns of fluid recharging and discharging the crust in the absence of basement relief (Figure 1). The details of driving forces due to sediment 
overlying a horizontal aquifer have been worked out by Rosenberg et al. [2000]; we concentrate on the driving forces associated with basement relief. The vigor and complexity of the fluid flow depends on the volcanic relief, the permeability structure of the volcanic basement, and the availability and distribution of outcrops that could expose permeable basement through the less permeable pelagic sediments.

[12] We illustrate the driving forces associated with a topographic high coupled with a constant bottom water temperature condition [Phillips, 1991]. For simplicity we assume that the volcanic edifice is below the thermocline and that the basal heat flux is constant. Relaxing both of these simplifications would increase the driving force. The volcanic ridge is parameterized in terms of a Gaussian ridge in Cartesian coordinates such that

$$
\xi(x)=H \exp \left(\frac{-x^{2}}{2 R^{2}}\right),
$$

where $\mathrm{H}$ is the amplitude and $\mathrm{R}$ is the characteristic width defined as $\mathrm{R}=0.6 \mathrm{H}$. We assume that the thermal gradient, $\Gamma$, is constant and that the isotherms are parallel to the topography. This will be approximately true for gentle topography and the assumption of a constant basal heat flux. With this approximation,

$$
\mathrm{T}(\mathrm{x}, \mathrm{z})=\Gamma(\xi(\mathrm{x})-\mathrm{z})
$$

and the horizontal temperature gradient is

$$
\frac{\partial T}{\partial x}=\Gamma \frac{\partial \xi(x)}{\partial x}=-\Gamma \frac{x}{R^{2}} H \exp \left(\frac{-x^{2}}{2 R^{2}}\right)=-\Gamma \frac{x}{R^{2}} \xi(x) .
$$

In this framework the pressure $\mathrm{P}$ is

$$
P=g(\xi(x)-z) \rho(T),
$$

where $\rho(\mathrm{T})$ is the fluid density as a function of temperature, $g$ is gravity. Density can be expressed as

$$
\rho(T)=\rho_{o}-\rho_{o} \alpha \Delta T,
$$

where $\alpha$ is the coefficient of thermal expansivity. The horizontal pressure gradient can be expressed as

$$
\frac{\partial P}{\partial x}=\frac{\partial P}{\partial T} \frac{\partial T}{\partial x}=-g \rho_{o} \alpha(\xi(x)-z) \frac{\partial T}{\partial x} .
$$

This equation is probably only good to an order of magnitude and depends on the degree to which isotherms parallel the topography. Equation (6) indicates that the driving force is proportional to the size of the feature and its horizontal temperature gradient. Figure 1 shows the topography and the horizontal pressure gradient at $\mathrm{z}=0$, the base of a small volcanic ridge. Negative values indicate that the pressure gradient is directed toward the origin. Even for a small volcanic ridge with low basal heat flux, the maximum driving force available is on the order of a kiloPascal (Figure 1), equivalent to that available on a well sedimented ridge flank [Fisher and Becker, 2000]. We also note that for sloping topography there is no minimum Rayleigh criteria. Because the specific discharge is proportional to the horizontal pressure gradient, these equations show that as the edifice is approached the driving force and the specific discharge increase. The resulting heat flow deficit is conceptualized with vectors drawn in Figure 1a. Numerical results of coupled heat and fluid flow simulations of this style are given in Harris et al. [2000b].

\section{Heat Flow Surveys}

[13] Widely spaced heat flow determinations collected for the purpose of measuring the thermal flux from hot spots have been published at four oceanic swells: Hawaii [Von Herzen et al., 1982, 1989], Bermuda [Detrick et al., 1986], Crozet [Courtney and Recq, 1986], and Cape Verde [Courtney and White, 1986]. These coarse surveys generally consist of about seven $\sim 10 \mathrm{~km}$ x $10 \mathrm{~km}$ regions, each with multiple (10-20) penetrations. Survey regions across each swell are separated by large distances (order $100 \mathrm{~km}$ ). This strategy was chosen with the supposition that heat flow should vary smoothly over large distances, that multiple penetrations would average out small-scale variability, and to optimize measurements over relatively large areas with limited ship time.

[14] It is now clear, however, that discriminating between environments where heat is transferred conductively or advectively with heat flow surveys requires closely spaced heat flow determinations (1-2 km or less) so that heat flow variability is more completely characterized. This characterization also requires that heat flow observations be collocated with seismic reflection profiles that provide detailed imaging of the crust - sediment interface so that basement, structural, and topographic influences on fluid flow can be discerned. Only two hot spot swells have heat flow surveys that approach these requirements, Hawaii [Harris et al., 2000a] and Reunion [Bonneville et al., 1997]. In both of these experiments seismic reflection profiles are single channel, and because the sediments in the flexural moat are thick and composed of volcaniclastic material shed from the edifice, the seismic data has relatively low resolution. We start by reviewing the closely spaced heat flow surveys at Hawaii and Reunion, and then apply these results to explore the widely spaced surveys at Hawaii, Bermuda, Crozet and Cape Verde.

\subsection{High-Resolution Surveys}

[15] Hawaii [Harris et al., 2000a] and Reunion [Bonneville et al., 1997] have closely spaced heat flow surveys collocated with seismic reflection profiles. The Hawaiian survey consists of two profiles, one north of Oahu and one north of Maro Reef (Figure 2). These surveys cross archipelagic aprons characterized by a thick wedge of volcaniclastic sediments deposited during mass wasting events and which overlie preexisting sediments and oceanic basement. Root mean square (RMS) variations along the Oahu and Maro Reef profiles are 15 and $5 \mathrm{~mW} \mathrm{~m}^{-2}$, respectively. Measurement uncertainty is estimated to be approximately $3 \mathrm{~mW} \mathrm{~m}{ }^{-2}$, indicating that the variability about the mean is significant. At a distance of $148 \mathrm{~km}$ along the profile, four repeat measurements were made to estimate instrumental variability. The standard deviation of these measurements is 

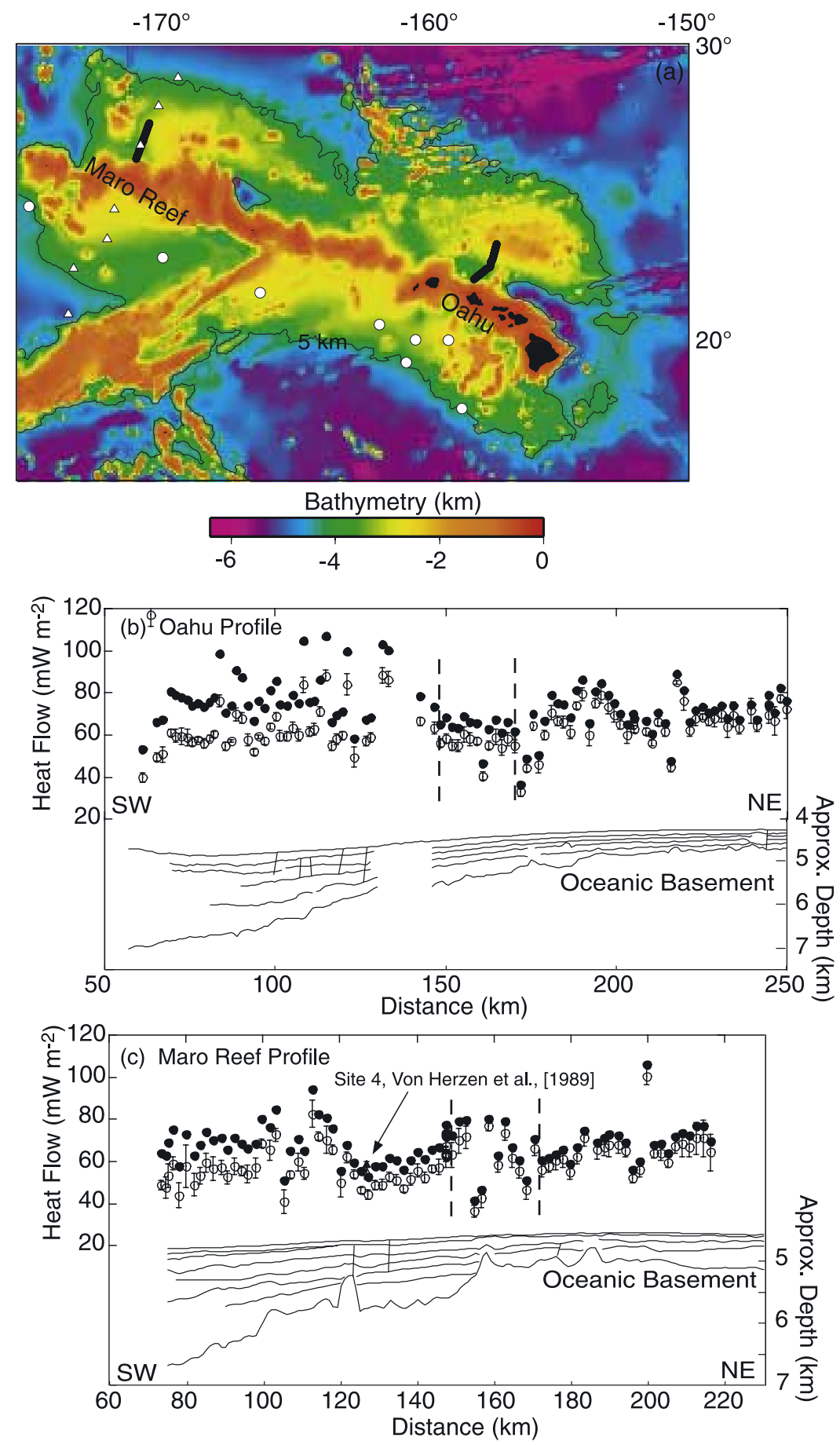

Figure 2. Thermal data from Hawaii. (a) Location of heat flow determinations. White symbols show location of data from South Arch (circles) and Maro Reef (triangles) [Von Herzen et al., 1982, 1989], and thick black lines show data from Harris et al. [2000a]. The white triangle colocated with the Maro Reef profile is site 4 of Von Herzen et al. [1989]. The extent of the Hawaiian swell is approximated with the $5 \mathrm{~km}$ bathymetric contour. Heat flow profile collocated with seismic reflection line for offshore (b) Oahu and (c) Maro Reef. Heat flow determinations uncorrected (open circles) and corrected for the effects of sedimentation (solid circles). Error bar represents standard deviation. Line drawings of depth-converted seismic reflection profile are shown in the lower portion of Figures $2 \mathrm{~b}$ and 2c [Harris et al., 2000a]. Vertical dashed lines show approximate divisions of Von Herzen [2004]. 


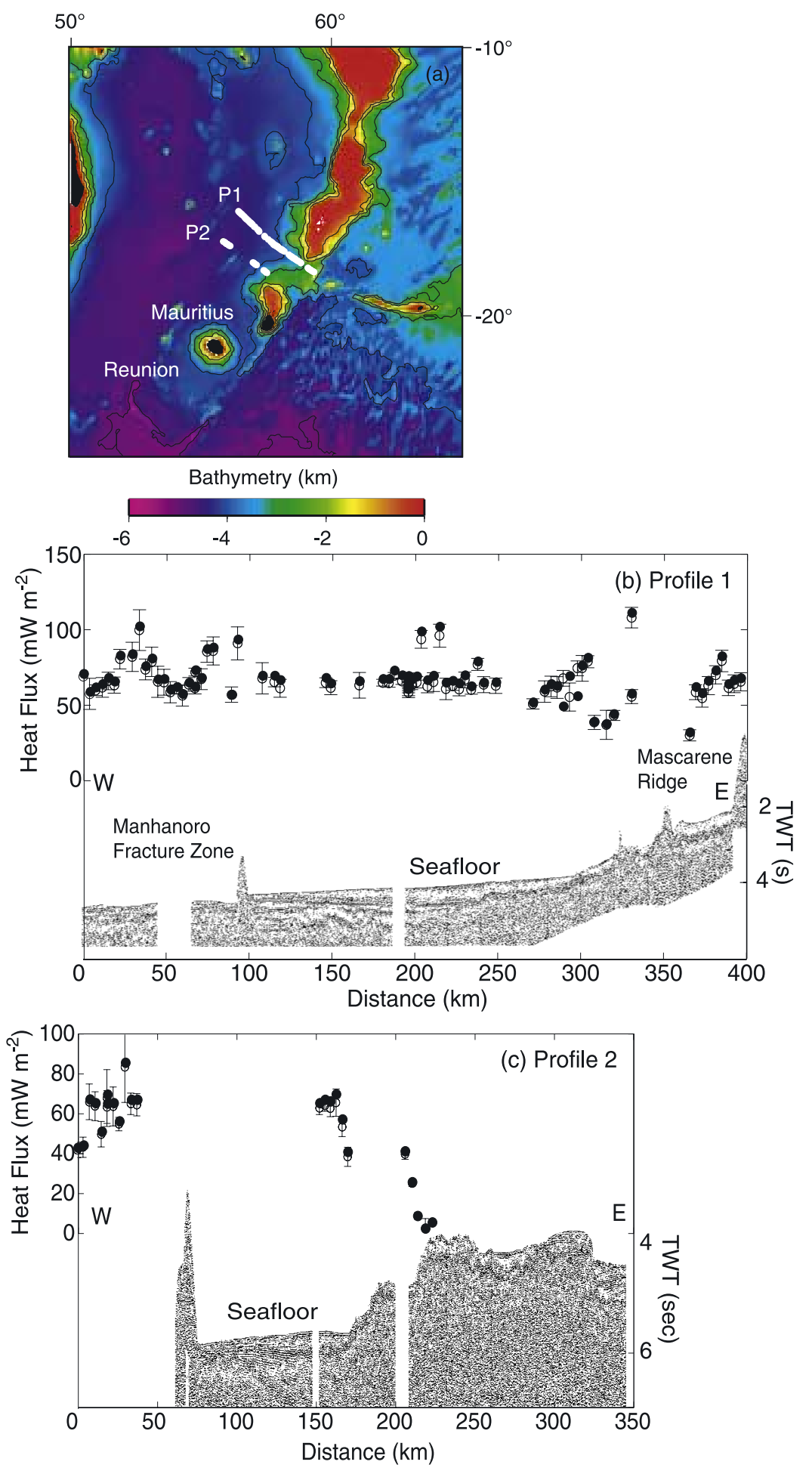

Figure 3. Thermal data from Reunion [Bonneville et al., 1997]. (a) Location of heat flow determinations at Reunion and heat flow determinations along profile 1 (b) and profile 2 (c). Heat flow determinations uncorrected (open circles) and corrected for the effects of sedimentation (solid circles). Error bar represents standard deviation. Seismic reflection data is also shown.

$0.4 \mathrm{~mW} \mathrm{~m}^{-2}$ also suggesting that the along profile variability is significant [Harris et al., 2000a]. The greatest variability along the Oahu profile comes from a series of single penetration anomalies that may be associated with fractures in the sediments allowing fluids to discharge. Significant variability along the Maro Reef profiles occurs inboard of prominent basement highs associated with the Murray Fracture Zone.

[16] The Reunion survey also consists of two profiles, both north of Mauritius (Figure 3). Sediment thickness varies between $360 \mathrm{~m}$ close to the Mascarene Ridge, to 


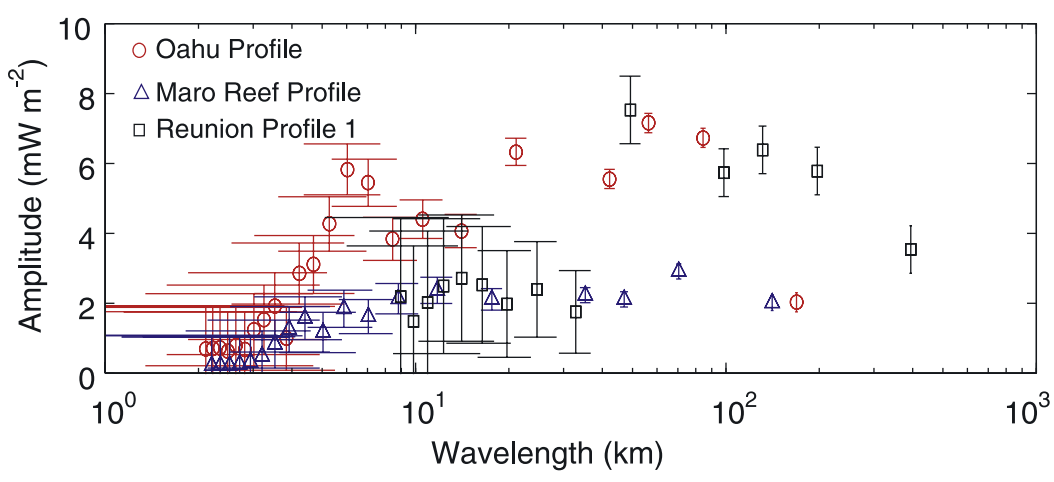

Figure 4. Spectral analysis of closely spaced heat flow profiles on hot spot swells. Vertical scale shows magnitude of harmonic coefficient and uncertainty. Spectral smoothing was accomplished through windowing four subsections of the original series. Note spectral peaks on order of $10 \mathrm{~km}$. Along the Oahu profile there is a strong peak at $7 \mathrm{~km}$, along the Maro Reef profile there is a subtle peak at approximately $10 \mathrm{~km}$, and along Reunion profile 1 there is a peak at approximately $50 \mathrm{~km}$.

approximately $2 \mathrm{~km}$ in isolated basins along the profiles. RMS variability along both profiles is approximately $13 \mathrm{~mW} \mathrm{~m}{ }^{-2}$, and the measurement uncertainty is estimated to be $7 \mathrm{~mW} \mathrm{~m}^{-2}$ [Bonneville et al., 1997]. A series of 5 repeat measurements at a single location yielded a standard deviation of $3 \mathrm{~mW} \mathrm{~m}^{-2}$. As with the Hawaii profiles, the variability is significant and not measurement noise. We focus on profile 1 where data coverage is more complete. As pointed out by Bonneville et al. [1997], variability appears correlated with basement topography and appears to reflect hydrothermal circulation. The greatest variability is associated with the Mascarene Ridge slope where basement is exposed at the seafloor.

[17] The spectra at both hot spots (Figure 4) are quite similar: most of the signal in the heat flow occurs at wavelengths less than a few hundred kilometers, and in each case there is a spectral peak at a wavelength on the order of $10 \mathrm{~km}$ suggesting a relatively shallow source of variability. These heat flow profiles reveal greater scatter than could plausibly be attributed to lateral or temporal variations in mantle heat flux and both sets of authors have noted that the variability is likely due to fluid flow [Harris et al., 2000b; Bonneville et al., 1997]. The data from both Oahu and Reunion, however, show power at longer wavelengths suggesting a second deeper source of variability.

[18] Harris et al. [2000a, 2000b] interpret the Oahu and Maro Reef profiles as indicating fluid flow in their entirety. In contrast, Von Herzen [2004] splits both profiles into three segments (Figure 2). The southern and northern segments of the Oahu profile are interpreted as displaying the effects of fluid flow, while the middle segment does not. The mean heat flow within the middle section is $64 \pm 6 \mathrm{~mW} \mathrm{~m}^{-2}$, while the mean heat flow in the southern and northern groups are $80 \pm 17$ and $71 \pm 11 \mathrm{~mW} \mathrm{~m}^{-2}$, respectively. This interpretation implies that the advectively disturbed sections are discharging heat. One interpretation (though not implied by Von Herzen [2004]) is that heated water is being expelled as the sediments compact. We note that in general this process is inefficient because of the finite volume of fluid, and that much of the heat is lost in warming the overlying sediments as the fluids rise to the surface. Along the Maro Reef profile the southern two segments indicate fluid flow with means and standard deviations of $64 \pm 4$ and $63 \pm$ $6 \mathrm{~mW} \mathrm{~m}^{-2}$, while the northernmost segment does not and has a mean and standard deviation of $65 \pm 5 \mathrm{~mW} \mathrm{~m}^{-2}$. If fluid flow is the source of variability, the smaller variability at Maro Reef, relative to Oahu, is consistent with the differences in the size of the edifice (equation (6)).

[19] Bonneville et al. [1997] note that on the eastern flank of the Mahanoro Fracture Zone (Figure 3), there is a pelagic platform that yields very consistent heat flow values with a standard deviation of $3.6 \mathrm{~mW} \mathrm{~m}^{-2}(\mathrm{n}=27)$. Two isolated penetrations give significantly higher values of heat flow, but these are attributed to incomplete penetration of the probe. Inboard of the platform, values are much more scattered with a standard deviation of $17 \mathrm{~mW} \mathrm{~m}^{-2}$. Notably, both sets of data yield the same mean value. Two interpretations are possible. The first, favored by Bonneville et al., is that heat flow values obtained from the pelagic platform represent background values. The scattered values on the Mascarene Ridge slope average to the background value so that there is no advective heat loss. The mean value is about $6 \mathrm{~mW} \mathrm{~m}^{-2}$ greater than that predicted by GDH1 [Stein and Stein, 1992] for this age of oceanic crust. Bonneville et al. [1997] invoke dynamic support with a component of lithospheric thinning to explain the data. However, the variability in this data also suggests significant fluid flow. Observed heat flow values may be depressed because of lateral fluid flow and advective heat loss. At Reunion, the spectra suggest that short wavelength variability associated with fluid flow may be superimposed on longer wavelength variations that could be associated with variations in basal heat flux or lithospheric thinning. It may be that the full amplitude of the variation in sublithospheric heat flux is obscured by the fluid flow.

[20] These closely spaced heat flow determinations provide evidence for shallow fluid circulation and help to identify its character at distance scales that are badly aliased in the earlier coarse surveys and smoothed out by averaging the results from multiple penetrations at the local sites. These profiles exhibit variability in excess of $25 \%$ of the mean used by Von Herzen [2004] as a basis for inferring fluid flow. The two important observations from all four of these heat flow profiles are that variability is significant and 


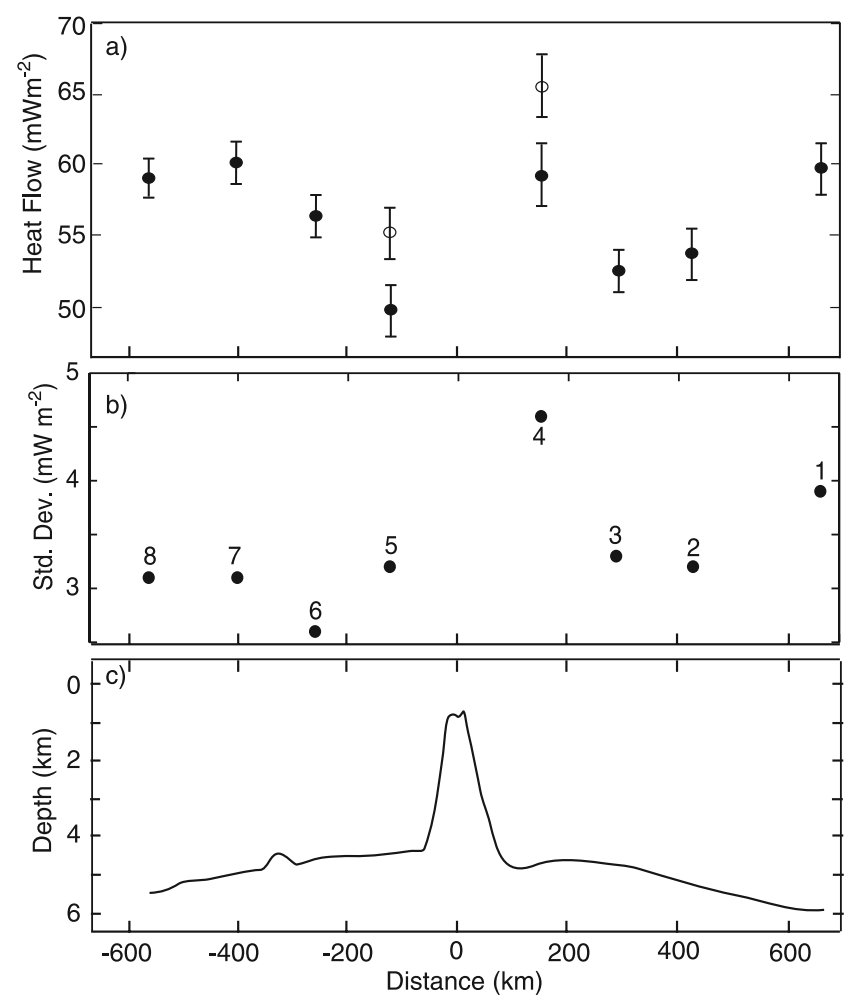

Figure 5. Coarse heat flow survey data from Maro Reef [Von Herzen et al., 1989]. (a) Mean heat flow values and 95\% confidence limits. Open symbols show alternative sediment correction. (b) Standard deviation of heat flow data at each station. (c) Bathymetry along Maro Reef profile.

increases toward the volcanic edifice. Both of these observations are consistent with buoyancy driven fluid flow and admit the possibility of advective heat loss.

\subsection{Coarse Surveys}

\subsubsection{Hawaii}

[21] The Hawaiian swell is a broad topographic high about $1.2 \mathrm{~km}$ above the regional bathymetry and with a width of 150 to $200 \mathrm{~km}$ (Figure 2). The swell subsides to the northwest in the direction of plate motion and is correlated with a geoid high that has a peak of about $5 \mathrm{~m}$ [Monnereau and Cazenave, 1990]. The first heat flow survey to methodically investigate the thermal influence of the hot spot swells [Detrick et al., 1981; Von Herzen et al., 1982] is located along the south arch of the Hawaiian swell. This survey indicates that heat flow values at the location of the hot spot reflect typical values for the 80- to 90-my-old oceanic crust, but then increase downstream of the hot spot to anomalously high values of approximately $10 \mathrm{~mW} \mathrm{~m}^{-2}$ relative to the plate model of Parsons and Sclater [1977]. With this plate model both the pattern of anomalous bathymetry and heat flow suggests a thermal origin of the hot spot swell [e.g., Crough, 1983]. However, relative to GDH1 the thermal anomaly is small to nonexistent [Stein and Stein, 1992].

[22] To better characterize the thermal anomaly, a subsequent survey perpendicular to the Hawaiian swell was conducted at Maro Reef (Figure 2) where the lithospheric heating effects of the hypothesized plume is expected to have the greatest surface effect [Von Herzen et al., 1989]. Assuming conductive heat transfer through the oceanic lithosphere, values of heat flow should vary systematically with bathymetry such that heat flow should be greater closer to the center of the hot spot swell. Surprisingly, values of heat flow along the profile actually decrease toward the center of the bathymetrically defined swell (Figure 5). Two features are suggestive of broad lateral fluid flow. The first is that, with the exception of station S4, values off swell are discernibly higher than values on the swell, and in general the variability of station data, as expressed by the standard deviation increases toward the volcanic edifice.

4.2.2. Cape Verde

[23] The Cape Verde rise is the highest observed oceanic swell. It is $2.2 \mathrm{~km}$ high and $1200 \mathrm{~km}$ wide and correlates with a geoid anomaly of about $8 \mathrm{~m}$ [Monnereau and Cazenave, 1990]. The Cape Verde Rise moves slowly in the hot spot reference frame, $12 \mathrm{~mm} \mathrm{yr}^{-1}$, and is located on old oceanic lithosphere, $125 \mathrm{Ma}$.

[24] Figure 6 shows the heat flow data collected on the Cape Verde Rise [Courtney and White, 1986]. Two-channel seismic reflection data were used to locate heat flow stations away from significant basement relief. Observed heat flow (with $95 \%$ confidence interval) varies from $45 \pm 3 \mathrm{~mW} \mathrm{~m}^{-2}$ on the abyssal plain (Site G) to $64 \pm 4 \mathrm{~mW} \mathrm{~m}^{-2}$ (Site C) near the peak geoid anomaly [Courtney and White, 1986]. In contrast to the Hawaiian and Reunion profiles, regional values of heat flow increase toward the geoid high. The standard deviation of the data increases with proximity to the volcanic edifice. We interpret Site $\mathrm{C}$ as being influenced by fluid flow, on the basis of its relatively larger standard deviation, consistent with the interpretation of Von Herzen [2004]. The mean of the Site C data is anomalously high by about $10 \mathrm{~mW} \mathrm{~m}^{-2}$ with respect to GDH1. The effects of fluid flow suggest that this mean may represent a minimum value.

\subsubsection{Bermuda}

[25] The Bermuda Rise in the western North Atlantic is an area of anomalously shallow bathymetry that peaks at about $800-1000 \mathrm{~m}$ and is $100-\mathrm{km}$ wide, centered approximately at the island of Bermuda. The geoid anomaly associated with the swell has an amplitude of $5 \mathrm{~m}$ and peaks about $150 \mathrm{~km}$ southeast of Bermuda. Bermuda is moving at a moderate speed of $25 \mathrm{~mm} \mathrm{yr}^{-1}$ in the hot spot frame of reference.

[26] The transect of heat flow stations approach Bermuda across lithosphere of ages between 110 and 160 M.y. (Figure 7). Detrick et al. [1986] made no age-related corrections to their measurements because the regional heat flow value appears to have approached an equilibrium value of $48-50 \mathrm{~mW} \mathrm{~m} \mathrm{~m}^{-2}$. The heat flow over Bermuda is marginally high by $8-10 \mathrm{~mW} \mathrm{~m} \mathrm{~m}^{-2}$. We interpret Sites 5 and 6 as being influenced by fluid flow, on the basis of their relatively larger standard deviation. This is consistent with the interpretation of Von Herzen [2004]. There is an intriguing inverse correlation between relatively high heat flow and standard deviation for these sites.

\subsubsection{Crozet}

[27] The Crozet Plateau (Figure 8) is an E-W trending shallow bathymetric feature east of the southwest Indian 

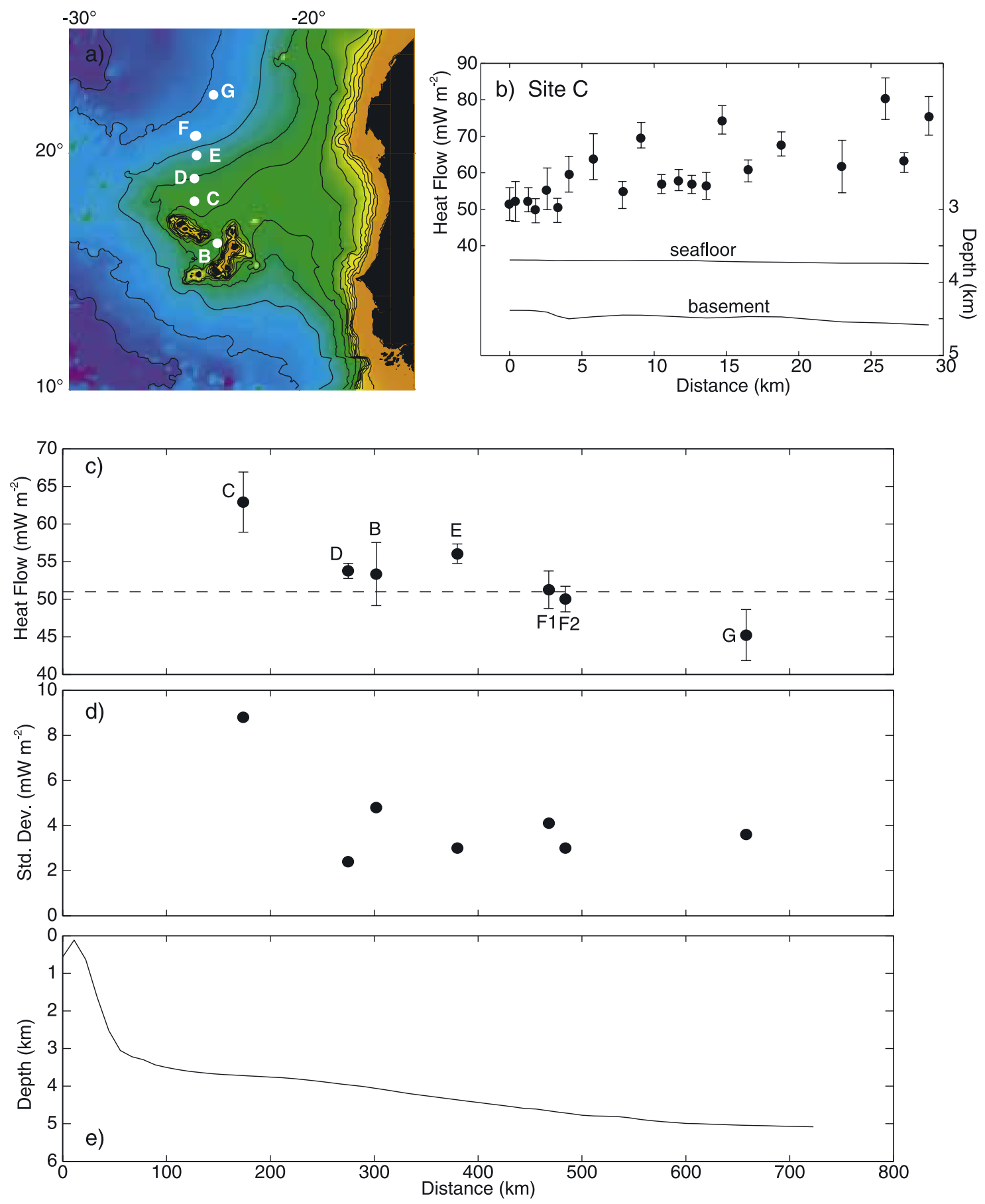

Figure 6. Thermal data from Cape Verde [Courtney and White, 1986]. (a) Location of heat flow determinations and bathymetry around Cape Verde. (b) Station data for heat flow site C. Error bars represent standard deviation. Seismic data is also shown. Modified from Von Herzen [2004]. (c) Averages of station data and 95\% confidence limits. (d) Standard deviation of station data. (e) Bathymetric profile along heat flow transect.

Ridge. Seismic refraction and an OBS study indicates eastward crustal thinning from 16.5 to $10 \mathrm{~km}$, and no underplated material has been detected [Goslin et al., 1981; Recq et al., 1998]. Seismic reflection profiles suggest relatively uniform sediments with thicknesses approximately $0.5 \mathrm{~km}$. Heat flow data [Courtney and Recq, 1986] were collected from the deep Crozet basin toward the center of the Crozet Plateau and positioned to overlie crust of $67 \mathrm{Ma}$.
At site M3 only one observation of heat flow was obtained, and this is suspect. At Site M4, individual determinations of heat flow (Figure 8) are generally consistent with no values falling more than 1 standard deviation from the mean, and the standard deviation of $5 \mathrm{~mW} \mathrm{~m}{ }^{-2}$ is not much higher than at the other stations. This station probably reflects conductive heat flow. Regionally, bathymetry increases from $4.4 \mathrm{~km}$ to $0.2 \mathrm{~km}$ depth toward the plateau (Figure 8) while 

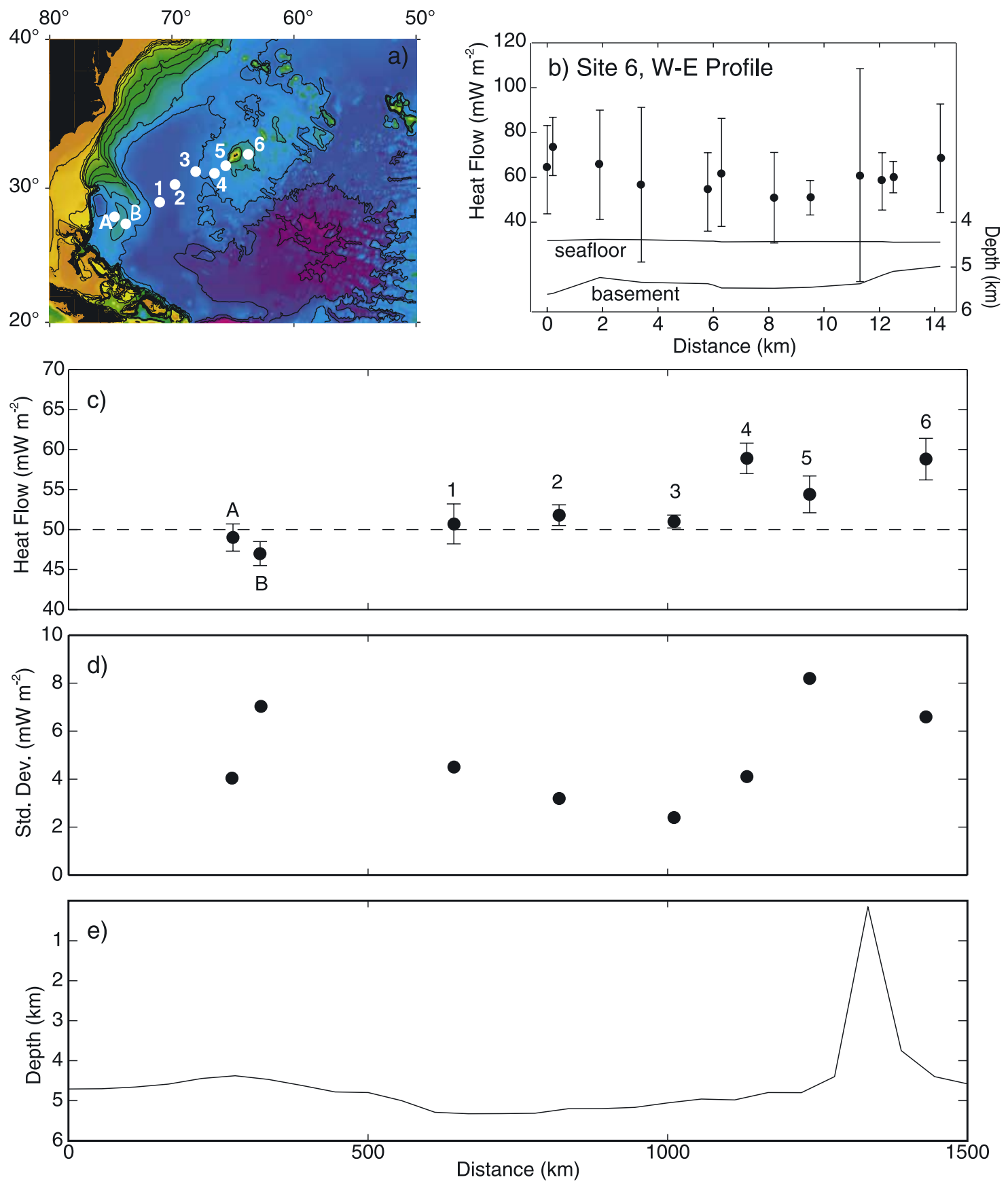

Figure 7. Thermal data from Bermuda [Detrick et al., 1986]. (a) Location of heat flow determinations and bathymetry around Cape Verde. (b) Station data for heat flow site C. Error bars represent standard deviation. Seismic data is also shown. Modified from Von Herzen [2004]. (c) Averages of station data and 95\% confidence limits. (d) Standard deviation of station data. (e) Bathymetric profile along heat flow transect.

heat flow heat flow increases by about $10-20 \mathrm{~mW} \mathrm{~m}^{-2}$, from $58 \mathrm{~mW} \mathrm{~m}^{-2}$ to $75 \mathrm{~mW} \mathrm{~m}^{-2}$ [Courtney and Recq, 1986]. Both bathymetry and heat flow are anomalous with respect to GDH1 predictions for $67 \mathrm{Ma}$. seafloor.

\section{Discussion}

[28] High-resolution heat flow surveys at Hawaii and Reunion show large variability that is difficult to reconcile with conductive heat transfer and likely reflects an environmental disturbance. Candidate environmental disturbances include (1) refractive heat conduction, (2) heat from recent volcanic intrusions, (3) debris flows or slumping, and (4) buoyancy driven fluid flow. Harris et al. [2000a] evaluated the variability observed in the Hawaii profile data with respect to these environmental disturbances and concluded that the variability is most likely due to fluid flow. This view is strengthened by the similarities to heat flow 

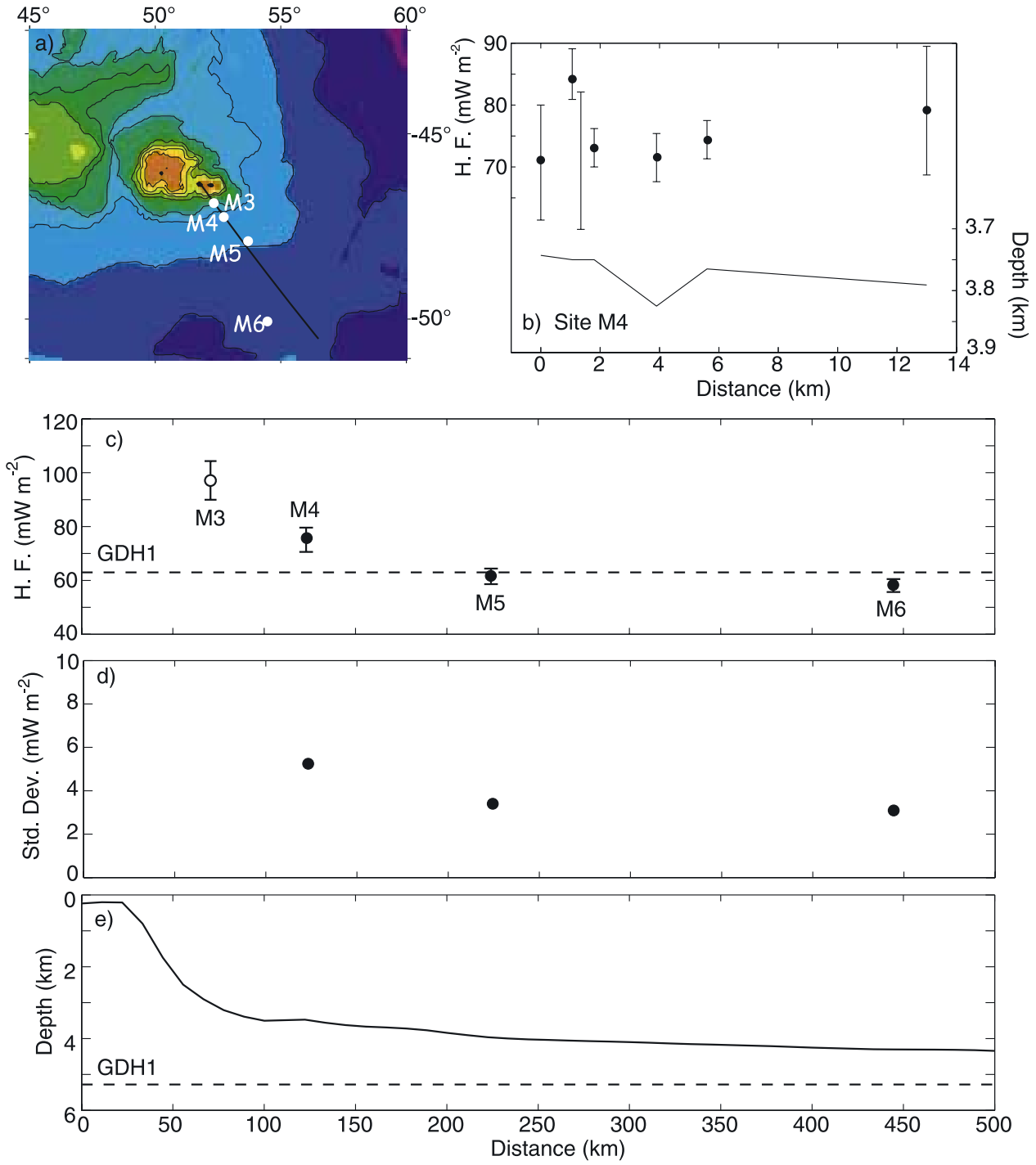

Figure 8. Thermal data from Crozet [Courtney and Recq, 1986]. (a) Location of heat flow determinations and bathymetry around Cape Verde. (b) Station data for heat flow site C. Error bars represent standard deviation. Bathymetry is also shown. Modified from Von Herzen [2004]. (c) Averages of heat flow station data and $95 \%$ confidence limits. The heat flow at station M3 is based on one penetration. (d) Standard deviation of station data. (e) Bathymetric profile along heat flow transect.

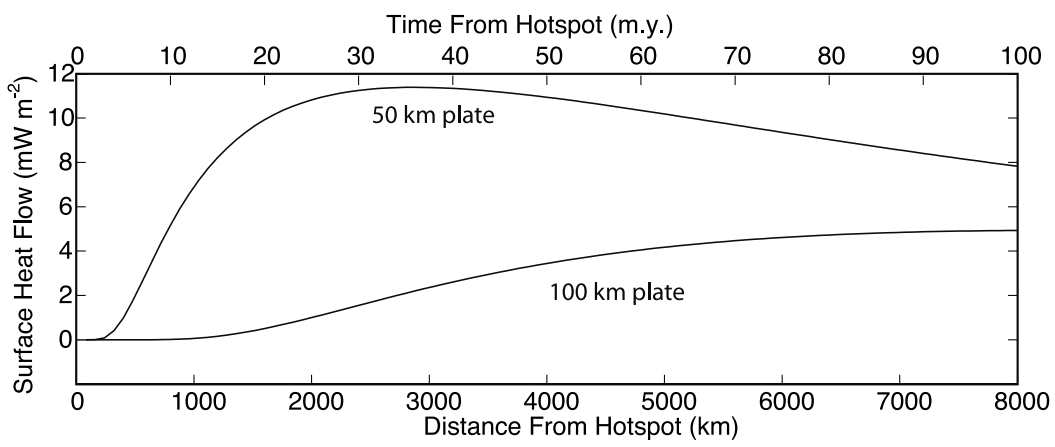

Figure 9. Theoretical anomalous heat flow at Hawaii (G. Ito, personal communication, 2005). Two models are shown. Both models assume a plume thickness of $100 \mathrm{~km}$ with an anomalous temperature of $300^{\circ}$ at the base of the lithosphere, and a lithospheric thermal conductivity of $4 \mathrm{~W} \mathrm{~m}^{-1} \mathrm{~K}^{-1}$. The more energetic model corresponds a lithosphere $50 \mathrm{~km}$ thick, whereas the less energetic model corresponds to a $100 \mathrm{~km}$ lithosphere. 


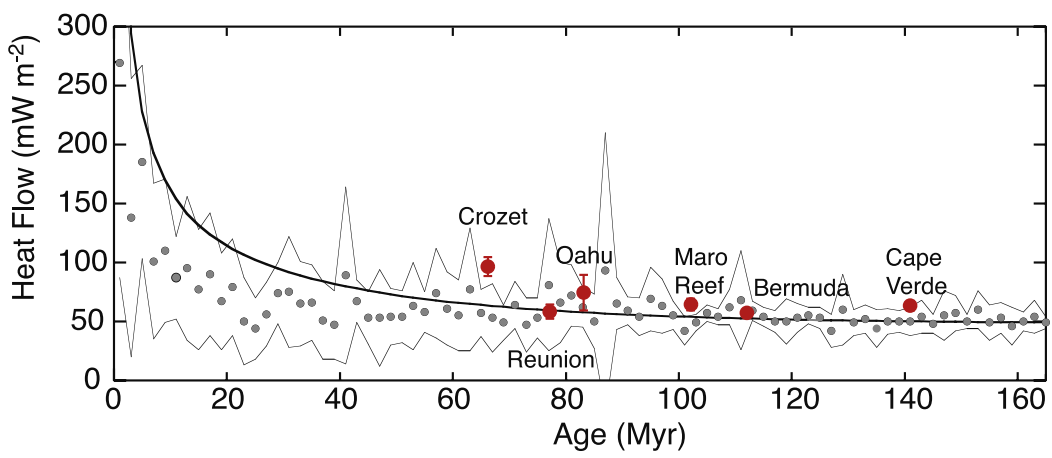

Figure 10. Marine heat flow data used for constructing GDH1 [Stein and Stein, 1992]. Circles show data in 2 my bins, and lines show standard deviation. Red circles show heat flow values closest to swell axis.

data collected at other hot spot swells. It is unlikely that refractive heat conduction can produce the observed variability [Von Herzen, 2004]. Both the high-resolution surveys and regional surveys all show increasing variability as the volcanic edifices are approached. Given the different ages and histories of the hot spot swells it would be highly fortuitous if each heat flow data set crossed a region of recent volcanic intrusion or debris flow or slumping. Our favored hypothesis is that fluid flow is perturbing the conductive thermal regime, and the most likely driving force for this fluid flow is associated with the bathymetric relief of the volcanic edifices.

[29] In addition to the large variability associated with the heat flow data, there are at least two other problems associated with using heat flow data to address the question of mantle plumes. These include the small expected thermal anomaly coupled with the uncertainty in the choice of a reference model. Anderson [2000] reviewed evidence on the magnitude of normal sublithospheric thermal anomalies and argued they fall with in a range of $\pm 200^{\circ} \mathrm{C}$. This is probably a liberal range. Geodynamic studies at Hawaii [Ribe and Christensen, 1999; Moore et al., 1999] predict modest if any thinning of the thermal lithosphere associated with the impingement of a plume. Figure 9 shows the conductive heat flow anomaly expected for a thermal conductivity of $4 \mathrm{~W} \mathrm{~m} \mathrm{~K}^{-1} \mathrm{~K}^{-1}$, and a $100 \mathrm{~km}$ thick layer of $300^{\circ} \mathrm{C}$ anomalous temperature under a lithospheric thickness of 50 and $100 \mathrm{~km}$. This figure shows that even with a generous magnitude of anomalous temperature and $50 \mathrm{~km}$ of lithospheric thinning, a heat flow anomaly at the Hawaiian swell would be difficult to identify.
[30] The choice of an appropriate reference model for the thermal evolution of oceanic lithosphere continues to receive attention, remains somewhat contentious, and depends in part on the overall objectives. Recent reviews of oceanic lithospheric cooling models include Harris and Chapman [2004], DeLaughter et al. [2005], and Hillier and Watts [2005]. The coolest reference model is the half-space cooling model [Davis and Lister, 1974] and the warmest model is GDH1 proposed by Stein and Stein [1992]. With increasing age of seafloor these models diverge and the difference at $100 \mathrm{Ma}$ is approximately $10 \mathrm{~mW} \mathrm{~m}^{-2}$. It is important to note however, that no single reference model provides a good fit to mean depth data between 0 and $165 \mathrm{Ma}$ [Carlson and Johnson, 1994], suggesting that the thermal history of oceanic plates is not simple and that no single model may be applicable [e.g., Nagihara et al., 1996; Ritzwoller et al., 2004].

[31] Figure 10 summarizes the mean heat flow value and standard deviation of station data closest to the hot spot axis using the GDH1 reference curve, the warmest of all plate models. With the exception of Crozet, and perhaps Maro Reef and Cape Verde, all of the near-swell-axis heat flow anomalies are within the uncertainties of the data and the GDH1 reference model, and have anomalies less than about $10 \mathrm{~mW} \mathrm{~m}^{-2}$ (Table 1). With cooler standard models, though, these anomalies are all greater than $10 \mathrm{~mW} \mathrm{~m}^{-2}$.

\section{Conclusions}

[32] We have examined individual heat flow values made on hot spot swells and find that the variability contained in these determinations is large. It appears that data collected using the coarse survey strategy, at intervals of $100 \mathrm{~km}$ or

Table 1. Summary of Hot Spot Heat Flow Data

\begin{tabular}{|c|c|c|c|c|c|}
\hline Hot Spot Swell & Age, Ma & 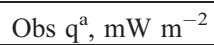 & GDH1 $\mathrm{mW} \mathrm{m}^{-2}$ & Anomaly $^{\mathrm{b}}, \mathrm{mW} \mathrm{m}{ }^{-2}$ & Reference \\
\hline \multicolumn{6}{|l|}{ Hawaii } \\
\hline Oahu & 83 & $74 \pm 15$ & 58 & $14 \pm 15$ & Harris et al. [2000a] \\
\hline Maro Reef & 102 & $64 \pm 15$ & 54 & $10 \pm 15$ & Harris et al. [2000a] \\
\hline Reunion & 77 & $58 \pm 6$ & 59 & $1 \pm 6$ & Bonneville et al. [1997] \\
\hline Cape Verde & 125 & $63 \pm 4$ & 50 & $13 \pm 4$ & Courtney and White [1986 \\
\hline Bermuda & 125 & $57 \pm 3$ & 50 & $7 \pm 3$ & Detrick et al. [1986] \\
\hline Crozet & 66 & $96 \pm 16$ & 63 & $33 \pm 16$ & Courtney and Recq [1986] \\
\hline
\end{tabular}

${ }^{\mathrm{a}}$ Heat flow: $\mathrm{q}$

${ }^{\mathrm{b}}$ Uncertainties on anomalies only reflect uncertainties on data and should be considered a minimum. 
more, have aliased a portion of the heat flow signal. Our preferred interpretation is that the variability is due to fluid flow. The presence of fluid flow admits the possibility that a component of basal heat flow is not being measured, analogous to the situation at ridge flanks. If this is the case, the mean observed heat flow is less than the actual lithospheric value and the full magnitude of sublithospheric thermal variations is not observed. However, without a firmly established reference model, a better understanding of buoyant support observed at hot spot swells, or additional data, this possibility is difficult to assess.

[33] Because the scatter in heat flow determinations is approximately the same magnitude as predicted variations in basal heat flow [e.g., Von Herzen et al., 1989], our ability to resolve anomalous basal heat flux will depend on a better understanding of environmental conditions and a thermal reference model. This understanding will likely require more high-resolution heat flow surveys collocated with seismic reflection lines, improved data processing, and more sophisticated modeling. Until then interpretations of heat flow data on hot spot swells based on conductive thermal models should be used with caution.

[34] Acknowledgments. We thank Alain Bonneville, Andrew Fisher, and Associate Editor Robert Duncan, whose helpful reviews clarified many points in the text.

\section{References}

Alt, J. C. (2004), Alteration of the upper oceanic crust: Mineralogy, chemistry, and processes, in Hydrogeology of the Ocean Lithosphere, edited by E. Davis and H. Elderfield, pp. 495-533, Cambridge Univ. Press, New York.

Anderson, D. L. (2000), The thermal state of the upper mantle: No role for mantle plumes, Geophys. Res. Lett., 27, 3623-3626.

Anderson, R. N., and M. A. Hobart (1976), The relation between heat flow, sediment thickness, and age in the eastern Pacific, J. Geophys. Res., 81, 2968-2989.

Anderson, R. N., and J. N. Skilbeck (1981), Oceanic heat flow, in The Seas, vol. 7, The Oceanic Lithosphere, edited by C. Emiliani, pp. 489-523, Wiley Intersci., New York.

Anderson, R. N., M. G. Langseth, and J. G. Sclater (1977), The mechanisms of heat transfer through the floor of the Indian Ocean, J. Geophys. Res., 82, 3391-3409.

Baker, P. A., P. M. Stout, M. Kastner, and H. Elderfield (1991), Largescale lateral advection of seawater through oceanic crust in the central equatorial Pacific, Earth Planet. Sci. Lett., 105, 522-533.

Bonatti, E. (1990), Not so hot 'hot spots' in the oceanic mantle, Science, 250, $107-111$.

Bonneville, A., R. P. Von Herzen, and F. Lucazeau (1997), Heat flow over Reunion hot spot track: Additional evidence for thermal rejuvenation of oceanic lithosphere, J. Geophys. Res., 102, 22,731-22,747.

Carlson, R. L., and H. P. Johnson (1994), On modeling the thermal evolution of the oceanic upper mantle: An assessment of the cooling plate model, J. Geophys. Res., 99, 3201-3214.

Courtney, R. C., and M. Recq (1986), Anomalous heat flow near the Crozet Plateau and mantle convection, Earth Planet. Sci. Lett., 79, 373-384.

Courtney, R. C., and R. S. White (1986), Anomalous heat flow and geoid across the Cape Verde rise: Evidence for dynamic support from a thermal plume in the mantle, Geophys. J. Int., 87, 815-867.

Crough, S. T. (1983), Hotspot swells, Annu. Rev. Earth. Planet. Sci., 11, $165-193$.

Davis, E. E., and D. S. Chapman (1996), Problems with imaging cellular hydrothermal convection in oceanic crust, Geophys. Res. Lett., 23, 3551-3554.

Davis, E. E., and C. L. B. Lister (1974), Fundamentals of ridge crest topography, Earth Planet. Sci. Lett., 21, 405-413.

Davis, E. E., D. S. Chapman, C. B. Forster, and H. Villinger (1989), Heatflow variations correlated with buried basement topography on the Juan de Fuca ridge flank, Nature, 342, 533-537.

DeLaughter, J., C. A. Stein, and S. Stein (2005), Hotspots: A view from the swells, in Plates, Plumes, and Paradigms, edited by G. R. Foulger et al., Geol. Soc. Amer. Spec. Pap., 388, 257-278, doi:10.1130/2005.2388(16).

DePaolo, D. J., and M. Manga (2003), Deep origin of hotspots: The mantle plume model, Science, 300, 920-921.
Detrick, R. S., and S. T. Crough (1978), Island subsidence, hot spots, and lithospheric thinning, J. Geophys. Res., 83, 1236-1244.

Detrick, R. S., R. P. Von Herzen, S. T. Crough, D. Epp, and U. Fehn (1981), Heat flow on the Hawaiian Swell and lithospheric reheating, Nature, 292, $142-143$.

Detrick, R. S., R. P. Von Herzen, B. Parsons, D. Sandwell, and M. Dougherty (1986), Heat flow observations on the Bermuda Rise and thermal models of midplate swells, J. Geophys. Res., 91, 3701-3723.

Elderfield, H., C. G. Wheat, M. J. Mottl, C. Monnin, and B. Spiro (1999), Fluid and geochemical transport through oceanic crust: A transect across the eastern flank of the Juan de Fuca Ridge, Earth Planet. Sci. Lett., 172, $151-169$.

Embley, R., M. Hobart, R. Anderson, and D. Abbott (1983), Anomalous heat flow in the northwest Atlantic, a case for continued hydrothermal circulation in 80 my crust, J. Geophys. Res., 88, 1067-1074.

Fisher, A. T. (1998), Permeability within basaltic oceanic crust, Rev. Geophys., 36, 143-182.

Fisher, A. T., and K. Becker (2000), Channelized fluid flow in oceanic crust reconciles heat-flow and permeability data, Nature, 403, 71-74.

Fisher, A. T., and R. P. Von Herzen (2005), Models of hydrothermal circulation within 106 Ma seafloor: Constraints on the vigor of fluid circulation and crustal properties, below the Madeira Abyssal Plain, Geochem. Geophys. Geosyst., 6, Q11001, doi:10.1029/2005GC001013.

Fisher, A. T., et al. (2003), Hydrothermal circulation across $50 \mathrm{~km}$ on a young ridge flank: The role of seamounts in guiding recharge and discharge at a crustal scale, Nature, 421, 618-621.

Foulger, G. R., and J. H. Natland (2003), Is 'hotspot' volcanism a consequence of plate tectonics?, Science, 300, 921-922.

Gallahan, W. E., and R. A. Duncan (1994), Spatial and temporal variability in crystallization of celadonites with the Trodos ophiolite, Cyprus: Implications for low-temperature alteration of the oceanic crust, J. Geophys. Res., 99, 3147-3161.

Goslin, J., M. Recq, and R. Schlich (1981), Structure profonde du plateau de Madagascar: Relations avec le plateau de Crozet, Tectonophysics, 76, $75-85$.

Green, D. H., and T. J. Falloon (2005), Primary magmas at mid-ocean ridges, "hot spots" and other intraplate settings: Constraints on mantle potential temperature, in Plates, Plumes, and Paradigms, edited by G. R. Foulger et al., Geol. Soc. Amer. Spec. Pap., 388, 217-247, doi:10.1130/ 2005.2388(14).

Harris, R. N., and D. S. Chapman (2004), Deep-seated oceanic heat flow, heat deficits, and hydrothermal circulation, in Hydrogeology of the Oceanic Lithosphere, edited by E. E. Davis and H. Elderfield, pp. 311-336, Cambridge Univ. Press, New York.

Harris, R. N., R. P. Von Herzen, M. K. McNutt, G. Garven, and K. Jordahl (2000a), Submarine hydrogeology of the Hawaiian archipelagic apron, 1: Heat flow patterns north of Oahu and Maro Reef, J. Geophys. Res., $105,21,353-21,369$.

Harris, R. N., G. Garven, J. Georgen, M. K. McNutt, and R. P. Von Herzen (2000b), Submarine hydrogeology of the Hawaiian archipelagic apron, 2: Numerical simulations of coupled heat transport and fluid flow, J. Geophys. Res., 105, 21,371-21,385.

Hillier, J. K., and A. B. Watts (2005), Relationship between depth and age in the North Pacific Ocean, J. Geophys. Res., 110, B02405, doi:10.1029/ 2004JB003406.

Jacobson, R. S. (1992), Impact of crustal evolution on changes of the seismic properties of the uppermost oceanic crust, Rev. Geophys., 30, 23-42.

Jarrard, R. D., L. J. Abrams, R. Pockalny, R. L. Larson, and T. Hirono (2003), Physical properties of upper oceanic crust: Ocean Drilling Program Hole $801 \mathrm{C}$ and the waning of hydrothermal circulation, J. Geophys. Res., 108(D7), 2188, doi:10.1029/2001JB001727.

Monnereau, M., and A. Cazenave (1990), Depth and geoid over oceanic hotspot swells: A global survey, J. Geophys. Res., 95, 15,429-15,438.

Moore, W. B., G. Schubert, and P. J. Tackley (1999), The role of rheology in lithospheric thinning by mantle plumes, Geophys. Res. Lett., 26, $1073-1076$

Morgan, W. J. (1971), Convection plumes in the lower mantle, Nature, 230, $42-43$.

Nagihara, S., C. R. B. Lister, and J. G. Sclater (1996), Reheating of old oceanic lithosphere: Deductions from observations, Earth Planet. Sci. Lett., 139, 91-104.

Noel, M., and M. W. Hounslow (1988), Heat flow evidence for hydrothermal convection in Cretaceous crust of the Madiera Abyssal Plain, Earth Planet Sci. Lett., 90, 77-86.

Parsons, B., and J. G. Sclater (1977), An analysis of the variation of ocean floor bathymetry and heat flow with age, J. Geophys. Res., 82, 803-827. Phillips, O. M. (1991), Flow and Reactions in Permeable Rocks, Cambridge Univ. Press, New York.

Presnall, D. C., and G. H. Gudfinnsson (2005), Carbonate-rich melts in the oceanic low-velocity zone and deep mantle, in Plates, Plumes, and 
Paradigms, edited by G. R. Foulger et al., Geol. Soc. Amer. Spec. Pap., 388, 207-216, doi:10.1130/2005.2388(13).

Recq, M., J. Goslin, R. Charvis, and S. Operto (1998), Small-scale crustal variability within an intraplate structure: The Crozet Bank (southern Indian Ocean), Geophys. J. Int., 134, 145-156.

Ribe, N. M., and U. R. Christensen (1999), The dynamical origin of the Hawaiian volcanism, Earth Planet. Sci. Lett., 171, 517-531.

Ritzwoller, M. H., N. M. Shapiro, and S.-J. Zhong (2004), Cooling history of the Pacific lithosphere, Earth Planet. Sci. Lett., 226, 69-84, doi:10.1016/j.eps1.2004.07.032

Rosenberg, N. D., A. T. Fisher, and J. S. Stein (2000), Large-scale lateral heat and fluid transport in the seafloor: revisiting the well-mixed aquifer model, Earth Planet. Sci. Lett., 182, 93-101.

Sclater, J. G., J. Crowe, and R. N. Anderson (1976), On the reliability of ocean heat flow averages, J. Geophys. Res., 81, 2997-3006.

Shipboard Scientific Party (2000a), Site 1149, Proc. Ocean Drill. Program Initial Rep., 185, 1-190.

Shipboard Scientific Party (2000b), Site 801, Proc. Ocean Drill. Program Initial Rep., 185, 1-222.

Spinelli, G. A., E. R. Giambalvo, and A. T. Fisher (2004), Sediment permeability, distribution, and influence on fluxes in oceanic basement, in Hydrogeology of the Oceanic Lithosphere, edited by E. E. Davis and H. Elderfield, pp. 151-188, Cambridge Univ. Press, New York.

Staudigel, H., K. Gillis, and R. Duncan (1986), K/Ar and Rb/Sr ages of celadonites from the Troodos ophiolite, Cyprus, Geology, 14, 72-75.

Stein, C. A., and S. Stein (1992), A model for the global variation in oceanic depth and heat flow with lithospheric age, Nature, 359, $123-129$.
Stein, C. A., and S. Stein (1993), Constraints on Pacific midplate swells from global depth-age and heat flow-age models, in The Mesozoic Pacific: Geology, Tectonics, and Volcanism, Geophys. Monogr. Ser., vol. 77, edited by M. S. Pringle et al., pp. 53-76, AGU, Washington, D. C.

Stein, C. A., and S. Stein (1994), Constraints on hydrothermal heat flux through the oceanic lithosphere from global heat flow, J. Geophys. Res., 99, 3081-3095.

Von Herzen, R. P. (2004), Geothermal evidence for continuing hydrothermal circulation in older (> 60 M.y.) ocean crust, in Hydrogeology of the Oceanic Lithosphere, edited by E. E. Davis and H. Elderfield, pp. 414447, Cambridge Univ. Press, New York.

Von Herzen, R. P., R. S. Detrick, S. T. Crough, D. Epp, and U. Fehn (1982), Thermal origin of the Hawaiian Swell: Heat flow evidence and thermal models, J. Geophys. Res., 87, 6711-6723.

Von Herzen, R. P., M. J. Cordery, R. S. Detrick, and C. Fang (1989), Heat flow and the thermal origin of hot spot swells: The Hawaiian Swell revisited, J. Geophys. Res., 94, 13,783-13,799.

Wolery, T. J., and N. H. Sleep (1976), Hydrothermal circulation and geochemical flux at mid-ocean ridges, J. Geol., 84, 249-275.

R. N. Harris, College of Oceanic and Atmospheric Sciences, Oregon State University, 104 COAS Administration Building, Corvallis, OR 97331-5503, USA. (rharris@coas.oregonstate.edu)

M. K. McNutt, Monterey Bay Aquarium Research Institute, 7700 Sandholdt Road, Moss Landing, CA 95039, USA. (mcnutt@mbari.org) 